\title{
A SIMULATION OF ORDER RESONANCE PHENOMENON IN A SUPPLY CHAIN TRIGGERED BY REINFORCING LOOP
}

\author{
Moon, S. ; Ji, W.*; Moon, H. ${ }^{* *} \&$ Kim, D. ${ }^{* * * \#}$ \\ *Defense Management, Korea National Defense University, Seoul, South Korea \\ ${ }^{* *}$ Industrial Engineering, Seoul National University, Seoul, South Korea \\ *** Department of International Trade, Pusan National University, Busan, South Korea \\ E-Mail: mseongam@hotmail.com, bohemiannnn@gmail.com, Hjmoon0710@snu.ac.kr, \\ ssskdj@hanmail.net ( ${ }^{\#}$ Corresponding author)
}

\begin{abstract}
A supply chain as a system has many subsystems. The subsystems include retailers, wholesalers, etc. Croson and Donohue say that the Bullwhip effect (order resonance phenomenon) can be caused by decision makers, not by exogenous variable changes. The purpose of this study is to show the process of collapsing the supply chain by interaction between subsystems, each of which has a balance loop with delay and a reinforcement loop under the oligopolistic competition. For this purpose we made a system dynamics simulation model assuming the supply chain with a wholesaler and two retailers. We give this model a single stimulus, check the activation and the dominance of each loop, and observe how it affects the entire system. The results showed that a single minor stimulus could ignite and therefore distract the whole system. In this process, delay and reinforcing loop has a key role. This study also showed that the oligopolistic competitive supply chain can cause the resonance in order flow.

(Received in July 2017, accepted in March 2018. This paper was with the authors 2 months for 3 revisions.)
\end{abstract}

Key Words: Supply Chain, Resonance Phenomenon, Oligopolistic Competition, System Dynamics, Reinforcing Loop, Balancing Loop

\section{INTRODUCTION}

Every supply chain shows order resonance phenomenon like Bullwhip effect where the variance of order quantities is amplified across the supply chain [1-10]. Most studies about the resonance have suggested multiple conceptual factors like delay, independent forecasting, shortage game, order batching, price fluctuations, and so on. Among them Croson and Donohue [5] is particularly interesting since it mentions that the resonance can be caused only by decision makers' control behaviour. And this is a theoretical base of our study.

The main purpose of this study is to investigate the generation mechanism of the resonance. We will try to define the conditions that can contribute to the decrease of the phenomenon. To understand the mechanism more clearly, we performed the simulation on a simple model. In this model, there is just one-time stimulus or change in the ordering process. The single stimulus influences on other participants' behaviours and also his ex/post decisions. We use the system dynamics simulation that can explain the continuum of such behaviours (e.g. loop).

It is supposed that resonance phenomenon can take place by reinforcing loop, not the balancing loop. Only shortage game among the causal factors of the phenomenon can make the reinforcing, and can happen in the structure of oligopolistic competition environment. In situations where inventory is sufficient, a minor stimulus cannot trigger the shortage game. Therefore we observe management behaviour when there is not enough stock. Lean management adopted by most companies is good condition for our model, as they can acquire the competitive advantage with low inventory through the rapid response [11-17]. Consequently we made a dyad oligopolistic competition supply chain which includes 1 wholesaler and 2 retailers. Each member operates lean management. 


\section{RESEARCH BACKGROUND}

\subsection{General control mechanisms in the supply chain}

In a typical supply chain, the consumer goods flow through a five echelon (material suppliers, manufacturers, distributors, wholesalers, and retailers). The length of echelons is dependent on the sales environment, product characteristics, and participant intention. For instance, Fisher [18] introduces two types of products, functional and innovative. The supply chain of a functional product is longer than that of innovative [7].

The multi-stage supply chain includes many participants which have also a lot of subsystems. The supply chain, the participants and the subsystems are also a system. It has some control tools in order to survive. Retailer or Wholesaler in the supply chain basically has an inventory system respectively.

An open system has feedbacks which make a loop. Loops are divided into positive and negative in accordance with the polarity. The positive loop is referred to as the reinforcing loop and the negative as balancing. When inventories are overflowed, retailer decreases the purchase quantity in sequence and the decrease causes the decrease of inventory. These behaviours make Inventory adjustment loop with minus polarity. Both supply line adjustment loop and backlog control loop are the typical balancing loops in the supply chain [4].

Fig. 1 is an example of reinforcing and balancing loop. The increase of birth adds the population and the more population makes the more birth. This relation continues without polarity change. This loop makes an exponential growth in Fig. 4. On the other hand, balancing loop makes the goal seeking behaviour. The higher death decreases the population whereas the lower population decreases death.

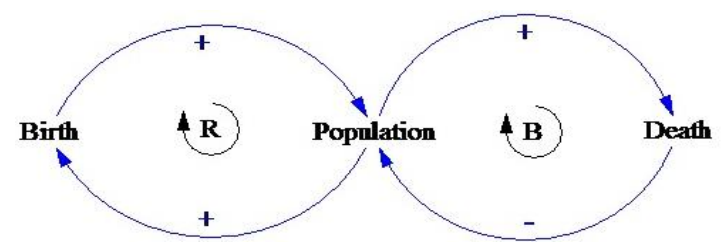

Figure 1: Reinforcing loop and balancing loop.

Through Fig. 2, you can see three loops in large. The loop to adjust by comparing the target inventory level and current inventory is the inventory control loop. That of the left side of the fig. is supply line control loop. The working mechanism is the same with the inventory control loop; in the right side of the figure is backlog loop. All loops presented in this figure have negative polarity, so to speak balancing loops. Depending on which loop is dominant changes the seeking value. The system with an only balancing loop seeks the target value.

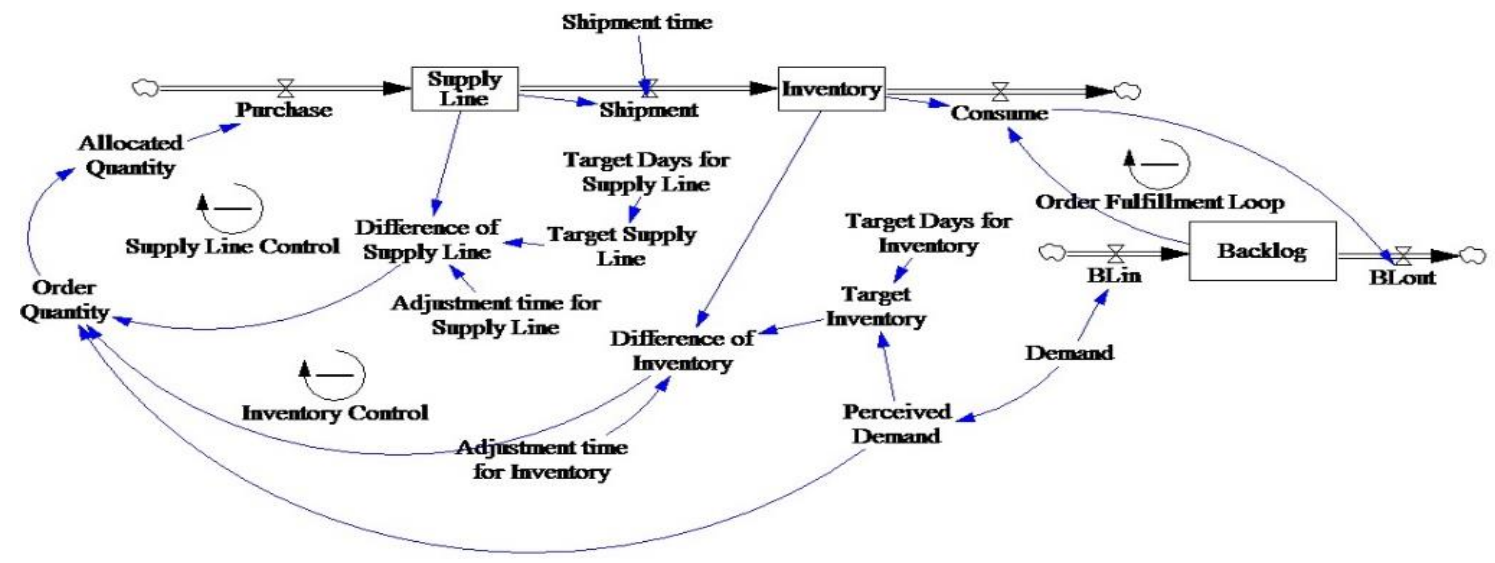

Figure 2: Sterman's inventory control module. 


\subsection{Resonance to disruption}

The supply chain may have reinforcing loops generated by the interaction between subsystems. Under the wholesaler's proportional allocation condition, if a retailer increases the order quantity to prevent an underage cost, the other retailer also should order more than the actual demand. This is called the shortage game loop. This is reinforcing loop because there are an even number of negative relationships. Shortage game causes the Bullwhip effect $[1,3,5,6,13,14]$. Especially Croson and Donohue [5] showed the interesting experimental results. They found the bullwhip effect still exists when normal operational causes (e.g., batching, price fluctuation, demand estimation etc.) are removed. It implies that the decision maker consistently underestimates the state of the supply line when making an order decision. On the other hand, the "bullwhip effect" in terms of empirical observations of the supply chain is described as a form of convective instability based on resonance effects [19].

An allocation may be easily described in the dyad market with one wholesaler and two retailers. When the sum of the two orders exceeds wholesaler's supply capacity (inventory), the wholesaler may have to allocate it. If the wholesaler is using the proportional allocation, and if retailers know the rules, they order more than the required to receive a larger allocation. Even if a retailer does not know the competitor's order quantity and allocable amount, the retailer can recognise the shortage by comparing his ordered and received quantities. He may increase the next order to compensate the shortage ratio. These increases of order quantity induce phantom orders.

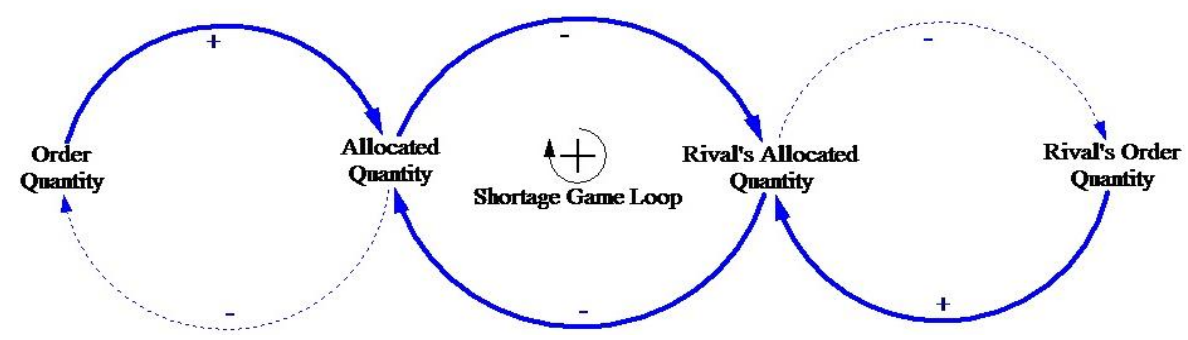

Figure 3: Shortage game loop.

Shortage game makes the reinforcing loop. In Fig. 3, if a retailer found the shortage, he would increase the order quantity. As the number of orders increases, the allocation increases, but the rivals decrease. Then the rival also will increase order quantity for more allocation. This loop continues until the underage rate reached to the zero. In Fig. 3, dot-line implies the conditional relationship. Less allocated quantity will increase the order quantity when shortage rate is over the zero. During one circulation, the polarity does not change (reinforcing loop).
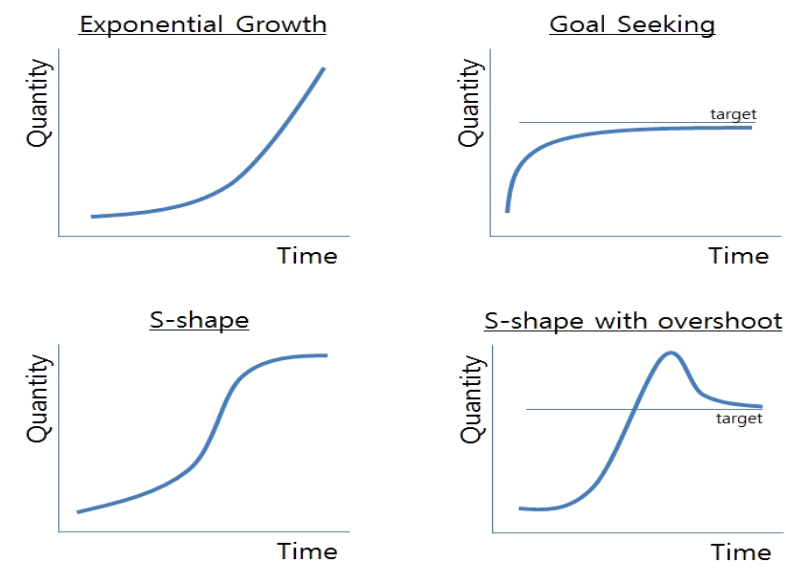

Figure 4: Examples of system behaviours by 1 or 2 loops. 
Fig. 4 shows the various behaviours made by just one loop or a combination of two loops [4]. The bottom left graph is when the system has both reinforcing and balancing loop. At first, it shows the exponential growth curves and then the goal seeking next. If it has an excessive delay in itself, it can take the right lower graph pattern. The overshoot in Fig. 4 is caused by a balancing loop and some delay.

A stimulus from a downstream or horizontal member has an influence on other participants' decision-making process. Without a balancing loop, the supply chain explodes by the resonance. Therefore the supply chain must have the balancing loop for resilience. Most studies on resilient system suggest that a resilient supply chain should be designed to minimise the outcome of disruption, and mention density, complexity, and node criticality should be considered in the designing process. Mitigation capability, which is determined by recovery and warning capability, can lower the disruption possibility [12, 14, 16, 20-25]. As a result, it can be inferred that there is at least one balance loop in the stable resilient system to minimise the outcome of the disruption and to prevent the explosion by resonance.

\subsection{Loop dominance analysis}

Behaviour over time in complex systems depends on the dominant feedback process of system. Sterman said that the concept of feedback-loop dominance is the key to the system dynamics paradigm [26].

The definitions of the loop dominance concept are diverse. In 1981 Richardson and Pugh [27] describe the behavioural definition of loop dominance as follow: "...a loop that is primarily responsible for model behaviour over some time interval is known as a dominant loop." Then Ford [28] later developed their definition. He adds specificity concerning 3 aspects: behaviour patterns, location of dominance, and gains. According to his theory, the purpose of feedback loop dominance analysis is to identify feedback structures that dominate behaviour. On the other hand, as with these various definitions, there are also methods for analysis of various loop dominance. In the past, most loop dominance analysis tools focus on model structure that links structure and behaviour. These structural approaches were not practical for difficult or critical size models, only to handle and apply some of the possible feedback structures (e.g. linear or two-loop systems) [28]. So in 1999 Ford proposed an important tool for explaining how the structure drives behaviour. His method uses a behavioural perspective to define dominance and identifies two important areas of feedback analysis: simultaneous dominance by multiple loops and shadow loop structures. In particular, he emphasized the understanding of feedback loop dominance, which balances the structural and behavioural perspectives.

In Ford's method, he uses three unique behaviour patterns based on the net rates of change of the variable of interest. The three patterns can be mathematically described as the derivatives of the values of the variable of interest (denoted $x$ ), and the net change rate is defined as the first derivative of the value of the variable $(\partial x / \partial t)$. In the most important definition, the second derivative of the variable represents the movement of the net change rate, which is defined as the atomic behaviour pattern in this methodology. The absolute second derivative values to describe behaviour greater and less than initial values produce the following definitions [28]: Linear atomic behaviour pattern $(\partial|\partial x / \partial t| / \partial t=0)$, Exponential atomic behaviour pattern $(\partial|\partial x / \partial t| / \partial t>0)$, Logarithmic atomic behaviour pattern $(|\partial x / \partial t| / \partial t<$ 0 ). To identify loop dominance at selected time interval, this analysis in behavioural approach uses changes in atomic behaviour patterns in the presence and absence of a feedback loop. After all, combination of the three atomic behaviour patterns can describe most behaviour simulated by system dynamics models. To investigate the general mechanism of resonance, this paper uses the feedback dominance analysis in behavioural approach proposed by Ford 
[28]. The detailed analysis is to identify the dominant loops by repeating the following eight steps during the selected time intervals.

Table I: Steps of analysis of loop dominance.

\begin{tabular}{|c|c|}
\hline Step & Details \\
\hline 1 & $\begin{array}{l}\text { - Identify the variable of interest; that will determine feedback loop dominance. } \\
\text { - } \text { Simulate the behaviour of the variable of interest. }\end{array}$ \\
\hline 2 & $\begin{array}{l}\text { - Identify a time interval; during which the variable displays only one atomic behaviour pattern. } \\
\text { - Define the conditions; in which dominance is specified the during this time interval. }\end{array}$ \\
\hline 3 & $\begin{array}{l}\text { - Identify the feedback loops; that influence the variable of interest. } \\
\text { - } \underline{\text { Select one of those feedback loops; as the candidate feedback loop. }}\end{array}$ \\
\hline 4 & $\begin{array}{l}\text { - Identify or create a control variable in the candidate feedback loop. } \\
\text { - Use the control variable to deactivate the candidate loop. }\end{array}$ \\
\hline 5 & $\begin{array}{l}\text { - Simulate the behaviour of the variable of interest over the reference time interval. } \\
\text { - Identify the atomic behaviour pattern or patterns of the variable of interest. }\end{array}$ \\
\hline \multirow{3}{*}{6} & - Identify time intervals: each of which contains a single atomic behaviour pattern. \\
\hline & 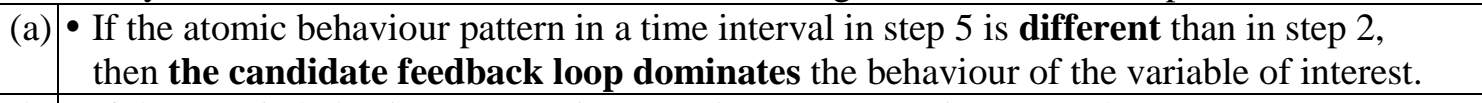 \\
\hline & $\begin{array}{l}\text { (b) }- \text { If the atomic behaviour pattern in step } 5 \text { is the same as in step 2, then: } \\
\text { i. The candidate feedback loop does not dominate. } \\
\text { ii. The candidate feedback loop dominates with a shadow feedback loop. }\end{array}$ \\
\hline 7 & - Repeat steps 3 through 6 ; to test for other dominances. \\
\hline 8 & - Repeat steps 1 through 7 for different time periods; to identify shifts of dominance. \\
\hline
\end{tabular}

\section{SIMULATION ASSUMPTIONS}

Dyad structure like Fig. 5 is a simple supply chain that represents vertical and horizontal relationships [29, 30]. The vertical relation is between wholesaler and retailer and the horizontal relation is between two retailers. In this base structure, the various loops shown in the research background are added.

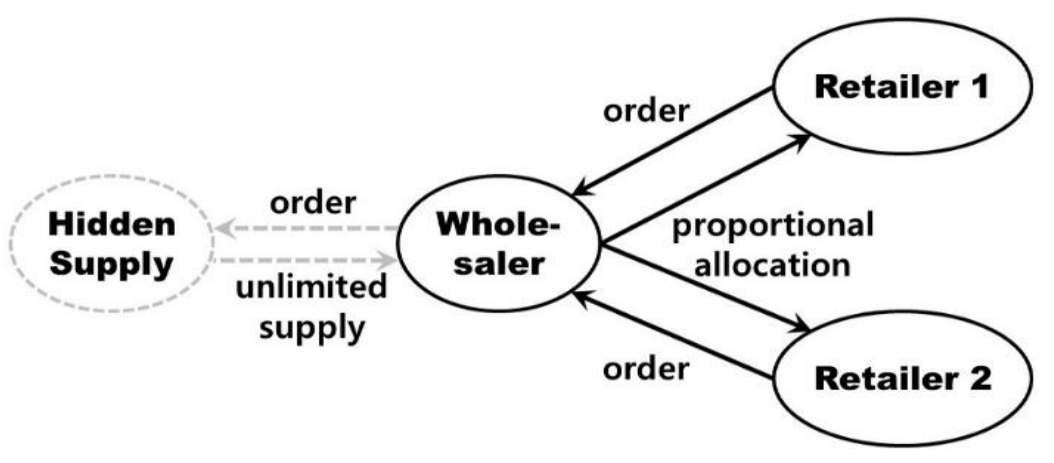

Figure 5: Oligopolistic competition supply chain.

When balancing loop coexists with reinforcing loop, the dominant loop determines the system pattern. S-shape appears when the dominance shifts from reinforcing loop to balancing loop. This is the combination of exponential growth and goal seeking. S-shape with overshoot includes two loops and delay. Delay can make the oscillation overshoot.

Assumptions of this simulation are as follows.

- We made a continuous inventory model not a discrete model. Unsold products can be sold the following day. And the supply inventories are adjusted simultaneously in the supply pipeline and in the stock storage stage. For this, we had to borrow the backlog loop from Sterman's beer distribution model [4]. Input equals expected output rate plus daily adjusted 
inventory. This means that if there is no change in output, there will be no change in input. When there is a difference between target and current stocks, it is smoothed and adjusted with delay.

- The inventory system is run by level up to model based on target-days and target-days is a constant. If target inventory is 100 and the average of demand is 5, the target-days is 20 . The target-days is based on lead-time and safety stock policy. In this model, the target-days of inventory has the same value with adjustment time of supply line. As a result, the adjustment time (days) is a core parameter influencing inventory level and responsiveness.

- Retailers can increase their order quantity for more allocation. They don't know the competitor's information. But they know wholesaler's allocation rule. This means that this model has a shortage game module. It is based on the fact that human has opportunism and bounded rationality.

- Wholesaler uses a proportional allocation rule. This is typical and makes shortage game between participants. According to proportional rule, higher orders result in more allocation quantities.

- There is no limit to the order quantity. Retailers and wholesaler can order as much as they want. But they cannot order less than zero. This implies that order cancelling is not allowed.

Based on the above assumptions, we made the following simulation (Fig. 6). All variables in this model have the equations expressed in Appendix, which represents the relationship with other variables.

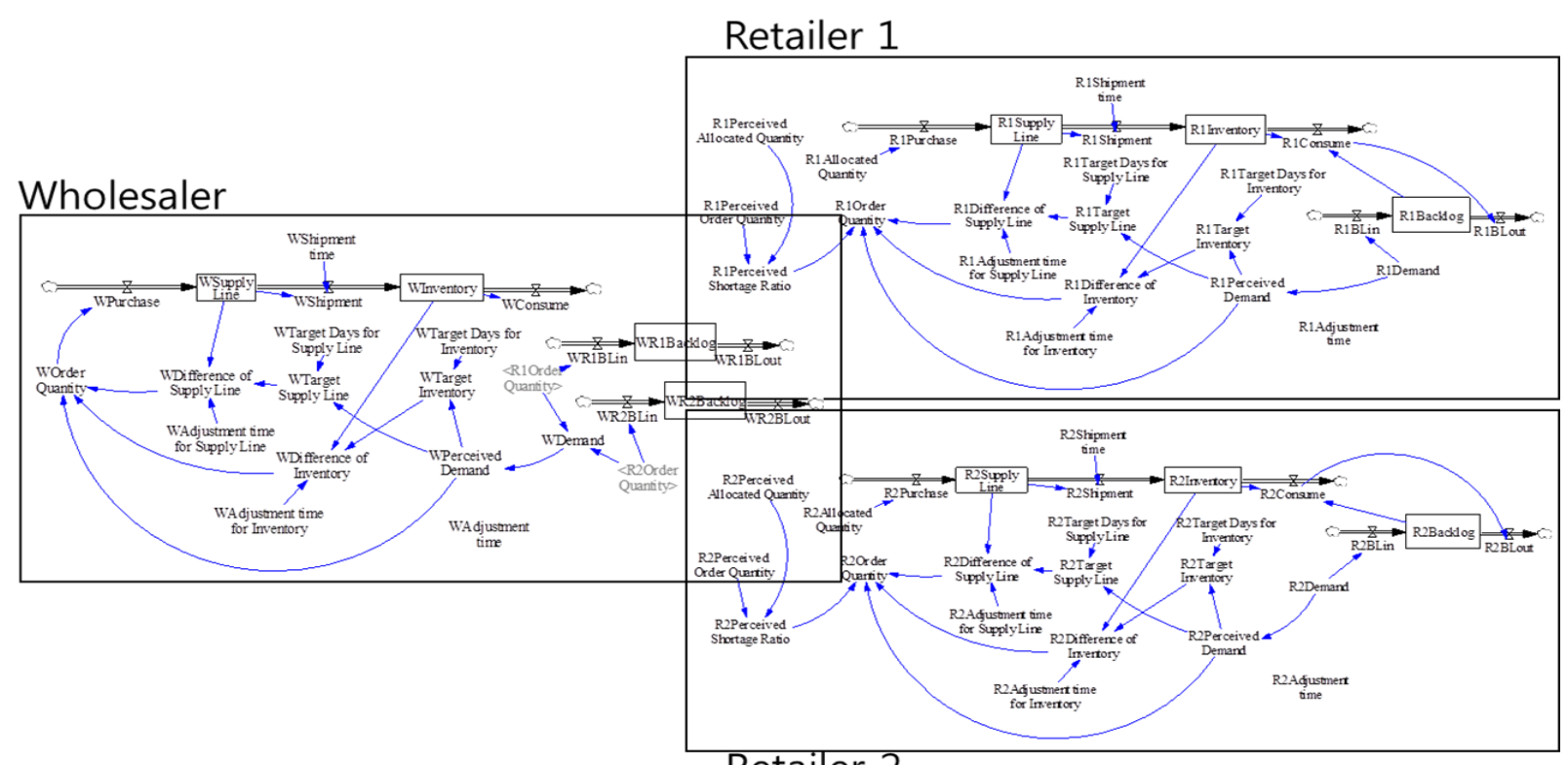

Retailer 2

Figure 6: Simulation model (Wholesaler, Retailer 1 and Retailer 2).

\section{SIMULATION RESULTS}

In this model, only one-time stimulus is given to one retailer, Retailer 1 . The STEP function is used in traditional Beer distribution game as a stimulus. Strictly speaking, in the step type stimuli are repeated again and again. The heights of stimuli are the same from start to end. On the other hand, stimulus takes place just one time in this model. During the total 200 days, a double consumption takes place in the only $11^{\text {th }}$ day. This is very small change compared to Beer game. The demand of retailer 1 is changed to 200, doubling the average demand of 100 per day. But $12^{\text {th }}$-day demand comes back to the usual average. The demand of retailer 2 has no change through the whole time. Each retailer orders to wholesaler every day and 
wholesaler also order to a hidden supplier without limitation every day. The demand to the wholesaler is the sum of the orders of retailers.

With the change of adjustment time from 10 days to 2 days, we observed the various stock variables as a result of the simulation. We focus on the each participant inventory which is representative of our model. And we checked the resilience of inventories.

In case when the adjustment time equals 10 days, the following variables have the same value: target days for inventory, target days for supply line, adjustment time for inventory, adjustment time for supply line, perceived demand, and shipment time. Every participant has the same value for these variables. If adjustment time is 10 days and demand is 100 , target demand is 1,000 . In the perspective of a dynamic inventory system, the difference between target inventory and on-hand inventory is divided by adjustment time. The inventory pattern of retailer 1 shows the typical resilient forms. Fig. 7 is the inventory of retailer 1 for adjustment time $=10,8,6$ and 4 days.

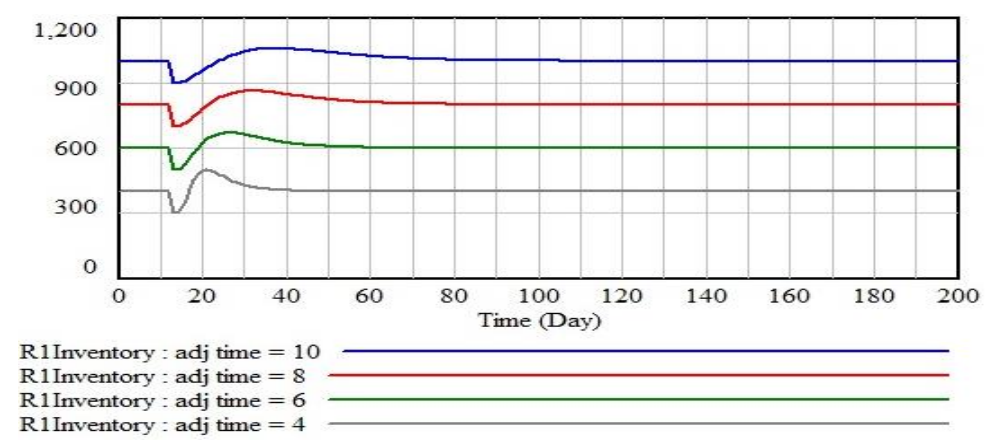

Figure 7: Retailer 1's inventory (adj. time $=10,8,6,4)$.

The inventories decrease suddenly because of additional demand. But they have the enough to cope with sudden demand. As you can see in Fig. 7, all graphs go through a vulnerable, resilient and overshoot period, and the state of inventories eventually reaches equilibrium. The length of adjustment time changes the resilient time and stable equilibrium time. The line of 10 days inventory has the longest period for equilibrium in this model. When adjustment time is 10 days, the stable time is almost 90 days. The bottom second line is for 6 days' adjustment time. The period is almost 30 days less than that of 10 days. There is a positive correlation between adjustment time and stable time, the size of overshoot and resilient time.

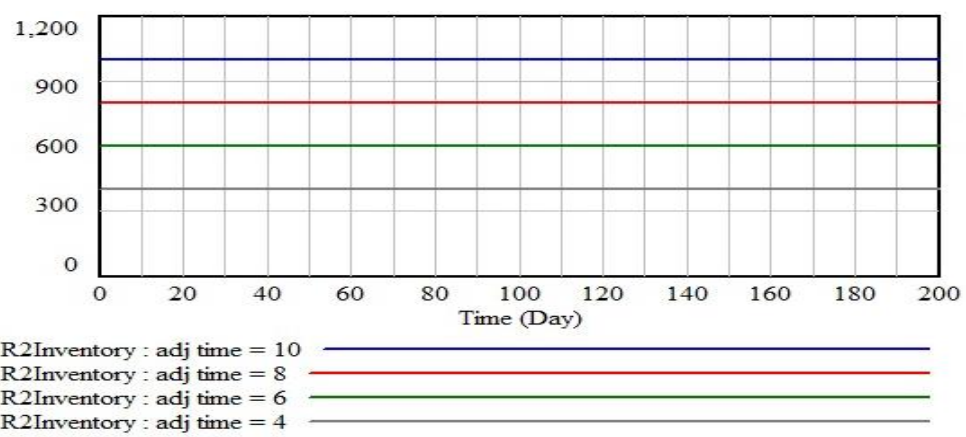

Figure 8: Retailer 2's inventory (adj. time $=10,8,6,4$ ).

Fig. 8 shows the retailer 2's inventory level does not change. The stimulus to the retailer 1 cannot change a bit of inventory of the retailer 2 . Wholesaler's inventory graph has the same shape with retailer 1's inventory. These graphs give us the validity of the model. All variables have the values we expected. Through the graphs, it is concluded that these systems are dominated by balancing loops. 
We decrease the adjustment time continuously with an expectation of dramatic change. Decreasing from 10 to 4 of adjustment time did not make the change. But at the 2 of adjustment time, the pattern of inventory shows a different shape. When adjustment time is 2 days, retailer 1 has an inventory level of 200 units, which is twice the average daily demand. This condition can trigger the reinforcing loop (shortage game loop). The retailer has only 200 units on the $10^{\text {th }}$ day but the demand of the $11^{\text {th }}$ day is 200 units. Retailer 1 's inventory falls down to 100 (Inventory system shows the value after getting input). On the $11^{\text {th }}$ day, the perceived demand, target inventory and target supply line increase over the 100 so that the necessary quantity is over than expected inventory. Therefore the retailer wants to control inventory level and order more than usual quantity. Although the order is the double, the wholesaler cannot supply as much as retailer 1's request because of its low-level inventory and delay. Retailer 1's shortage experience pushes order quantity up until he gets enough inventory. Retailer 2 also amplifies his own order quantity with the shortage experience. Fig. 9 is the Retailer 1's inventory in case adjustment time is 4 or 2 day.

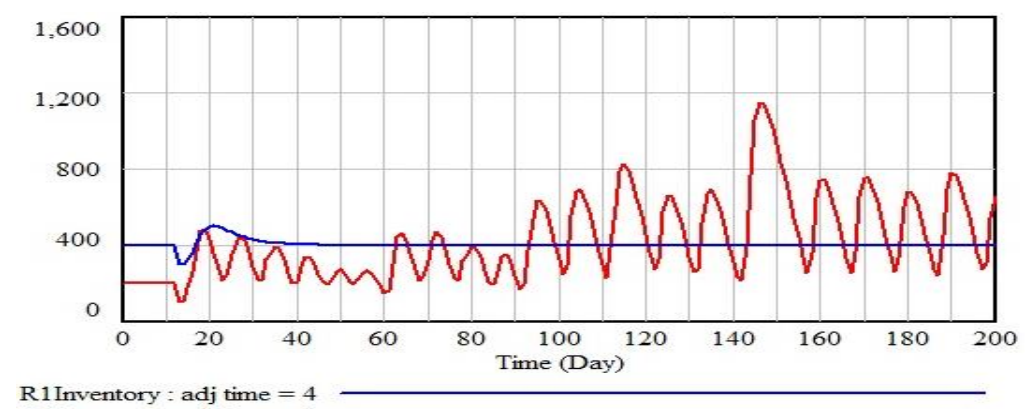

R1Inventory : adj time $=2$

Figure 9: Retailer 1's inventory (adj. time = 4, 2 days).

When adjustment time is 4 days, Retailer 1's inventory line has a simple but dynamic as time flows. It shows vulnerability, resilience, overshoot and equilibrium process with short shape compared to 10 days line. You can see the pattern change from adjustment time 2's line in Fig. 9. The line is oscillated and shows a pattern that was not seen in the previous graphs. It is not a typical resilient process. This pattern is not stable anymore. We only reduced the number of days, but this shows not only fluctuations but also uncertain up-downs. Retailer 2's graph pattern is the same as retailer 1's. Adjustment time (2 days) can trigger the retailer 2's shortage game loop. The endless game loop dominance has limited by other balancing loops.

The inventory graph of wholesaler also has the same pattern as previous two. Fig. 10 shows the pattern for all cases when adjustment time is 2 days. And we can see the height of inventory fluctuation in the wholesaler is beyond expectation. The inventory lines with 2-day target often exceed 1,000 units. The resonance effect can be inferred from the fact that the highest height of the swing in the wholesaler line is greater than the sum of the highest height of each retailer's swing.

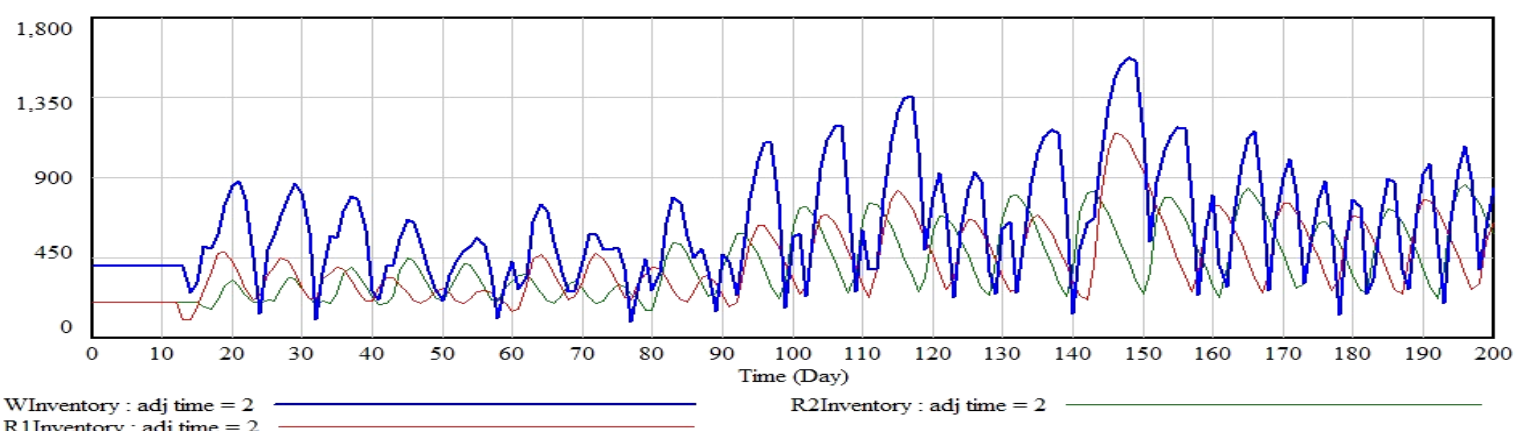

R1Inventory : adj time $=2$

Figure 10: Retailers' and wholesaler's inventory lines (adj. time $=2$ days). 
It is necessary to analyse the behaviours of retailers and wholesaler to investigate the generation mechanism of resonance phenomenon. Fig. 11 shows the order quantity lines. For readability of the graph, it presented only for 100 days.

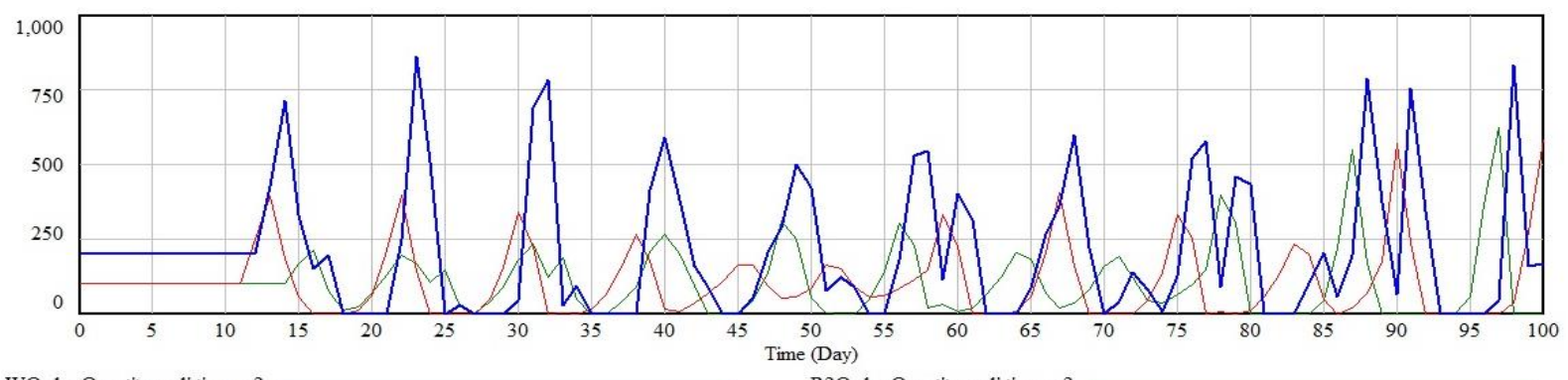

WOrder Quantity : adj time $=2$

R1Order Quantity : adj time $=2$

Figure 11: Retailers and wholesaler order quantity (adj. time $=2$ ).

In Fig. 11, we can see the fact (in process of shortage game between retailers) that between 18 and 28 days the peak height of the wholesaler's wave exceeds the sum of the wave maximums of each retailer. Even though only one stimulus is given as with adjustment times 4 to 10 , certainly the wave height of wholesaler order quantities is higher than that of the sum of retailers' waves.

\section{VERIFICATION WITH A BEHAVIOURAL APPROACH TO FEEDBACK LOOP DOMINANCE ANALYSIS}

Loop dominance analysis approach in this paper model follows Ford's 8 step analysis.

\section{$\underline{\text { Step } 1}$}

The main purpose of this study is obtaining the generation mechanism of the resonance. And we anticipate that the resonance phenomenon can take place by reinforcing loop. Therefore based on the simulation results of this paper (especially Fig. 14), we can choose the variable, Wholesaler Order Quantity, as the variable of interest in our simulation model.

\section{$\underline{\text { Step } 2}$}

In order to distinguish the atomic behaviour pattern of the selected variables, the analysis period was limited to the time interval from the initial 21 days to 28 days. Fig. 12 shows that the peak height of the wholesaler's wave is larger than the sum of the wave maximums of each retailer.

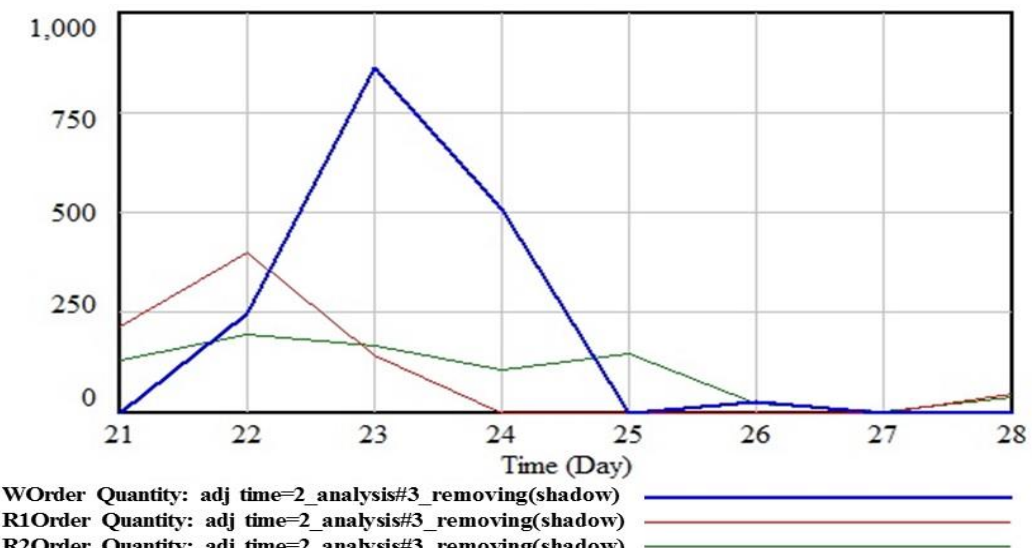

ROAer Quanty: adj

Figure 12: Retailers and wholesaler order quantity (adj. time $=2$ ). 


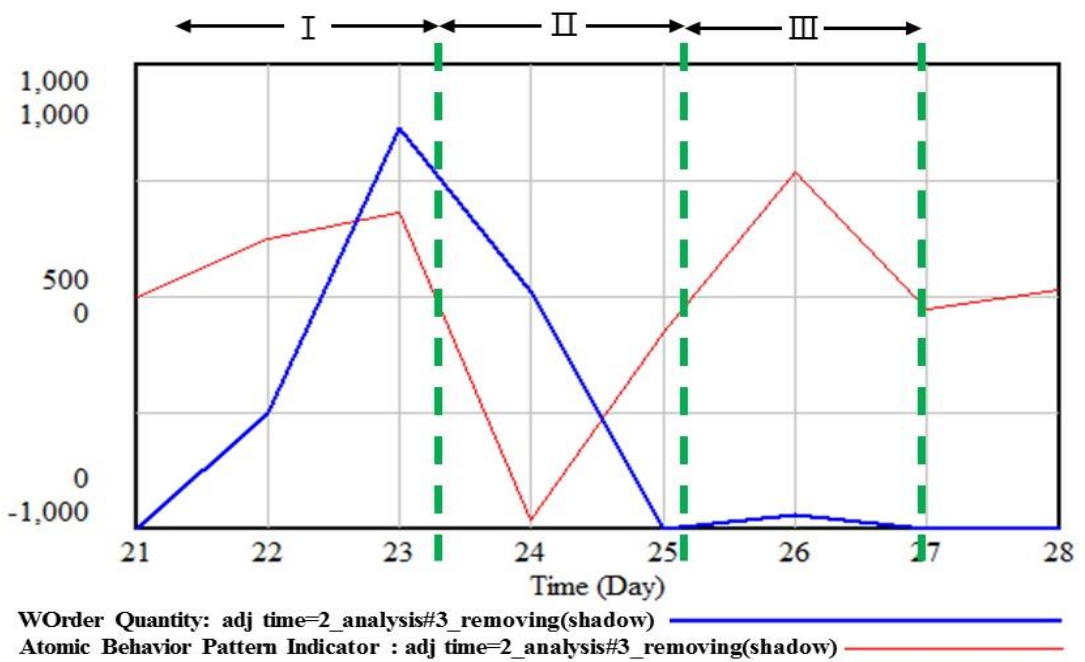

Figure 13: Reference/atomic behaviour of wholesaler.

And we also observed the second derivative graph in this section during same time interval in Fig. 13. The entire graph can be divided into three sections (I III) according to the value of the atomic behaviour pattern indicator. In section I of Fig. 13, the value has a positive, which indicates that the behaviour pattern of the wholesaler order quantity is exponential. According to Ford's definition, this is the exponential atomic behaviour pattern. And the atomic behaviour pattern changes polarity for 23 to 24 days. The end of section I corresponds to the inflection point of the "S"-shaped rise in the wholesaler order quantity. The limits of the section coincide with the dominance shift times indicated by the behavioural method for the Wholesaler order quantity in the same section.

\section{$\underline{\text { Step } 3}$}

The model of this paper has a total of 92 independent feedback loops containing the wholesaler order quantity. Among the entire loops one loop is chosen, which is the minimum loop containing order variables from the wholesaler and retailer. The loop is: 'WOrder_Quantity' $\rightarrow$ 'WPurchase' $\rightarrow$ 'WSupply_Line' $\rightarrow$ 'WShipment' $\rightarrow$ 'WInventory' $\rightarrow$ 'RlAllocated_Quantity' $\rightarrow$ 'R1Perceived_Allocated_Quantity' $\rightarrow$ 'R1Perceived_Allocated_Quantity' $\rightarrow$ 'R1Perceived_Shortage_Ratio' $\rightarrow$ 'R1Order_Quantity' $\rightarrow$ 'WDemand' $\rightarrow$ 'WPerceived_Demand' $\rightarrow$ 'WOrder_Quantity'

\section{$\underline{\text { Step } 4}$}

In further simulations for testing, this loop is deactivated by changing the link equation between 'R1Order_Quantity' variable and 'R1Perceived_Shortage_Ratio' variable as follow.

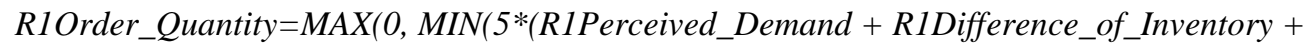
R1Difference_of_Supply_Line),XIDZ(R1Perceived_Demand +R1Difference_of_Inventory + RlDifference_of_Supply_Line, 1 - RlPerceived_Shortage_Ratio, RlPerceived_Demand + R1Difference_of_Inventory + R1Difference_of_Supply_Line)))
}

In the previous basic equation, only the 'R1Perceived_Shortage_Ratio' variable belonging to the XIDZ function is removed. The function represented by 'XIDZ(A, B, X)' returns A divided by $B$. If $B$ is zero, then returns $X$.

\section{$\underline{\text { Step } 5}$}

As a result of the additional simulation, Fig. 14 shows the behaviour that reflects a deactivated link between the 'R1_Order_Quantity' variable and the 'R1_Perceived_Shortage _Ratio' variable. First of all, we can see that the maximum number of orders from wholesalers has decreased to less than 500. In particular, compared to previous simulations, the resonance of the Wholesaler order has almost disappeared between 21 and 28 days. 


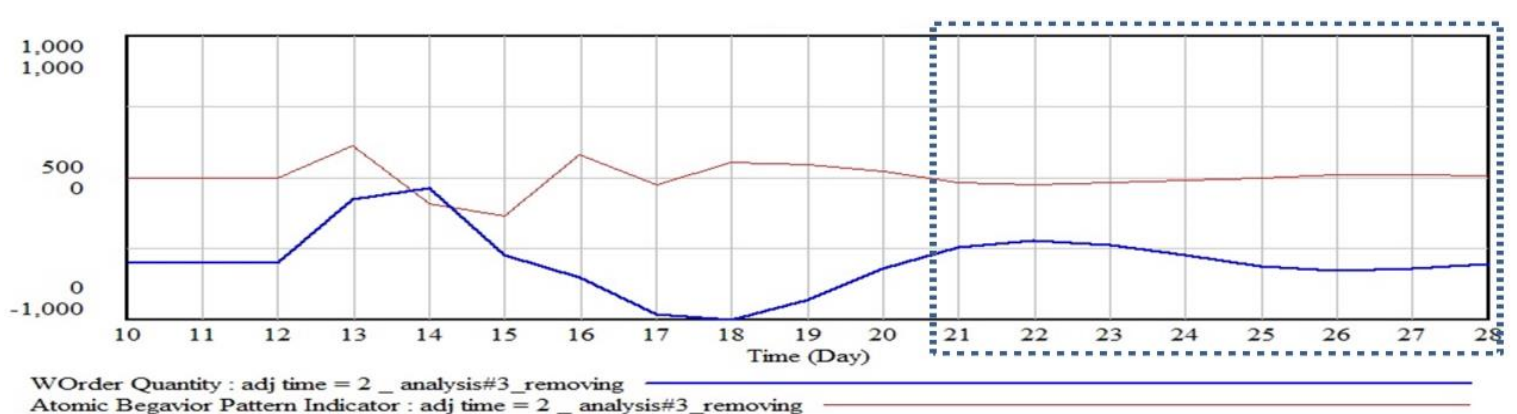

Figure 14: Reference behaviour in Step 5.

\section{$\underline{\text { Step } 6}$}

The change in atomic behaviour pattern from exponential to almost linear (with a second derivative of almost 0) implies that the loop used in Step 3 dominates the behaviour of the variable of interest. This means that the effect of Retailer 1's perceived shortage ratio dominates over the observed time interval.

\section{$\underline{\text { Step } 7}$}

As with the perceived shortage ratio effect of Retailer 1, additional testing of the impact of Retailer 2 is required. This is because the loop containing the perceived shortage ratio effect of Retailer 2 can be dominated simultaneously with Retailer 1 . To test additionally, the loop used in Step 3 is reactivated and the test repeated with the another loop as the candidate loop by cutting the link between 'R2Order_Quantity_variable' and 'R2Perceived_Shortage_Ratio' variable like Step 4.

In Fig. 15, the atomic behaviour pattern with the loop inactive remains unchanged over the time interval 10-28 days, maintaining the exponential pattern. This indicates that loop affected by the effect of Retailer 2 does not dominate that time interval. Retailer 1 only has a temporary increase in orders, and Retailer 2 has no change in the order, so it is natural that it is not affected.

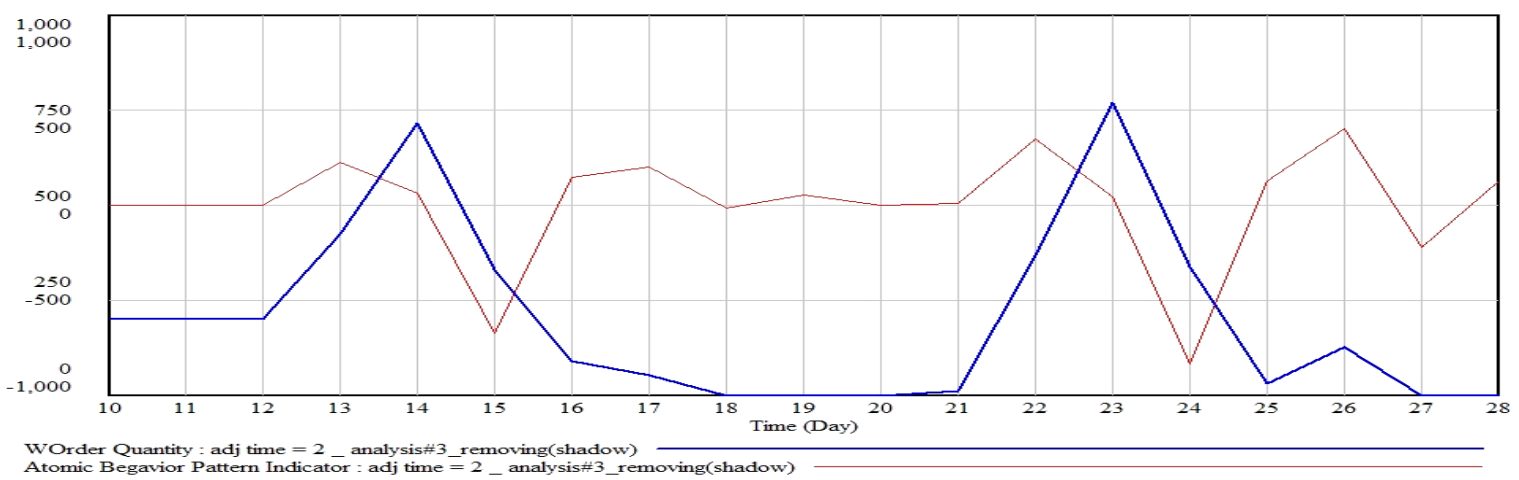

Figure 15: Reference behaviour in Step 7.

The previous simulation results show that loop used in Step 5, which is affected by the effect of Retailer 1's perceived shortage ratio, dominates the entire observation period. In summary, from a behavioural analysis perspective loop with the effect of Retailer 1's perceived shortage ratio can be the factor that dominates the resonance phenomenon of this model.

\section{$\underline{\text { Step } 8}$}

According to the methodology, this step requires to repeat steps 1 to 7 for different periods. In this model, the pattern during the previously observed interval is also repeated in the other interval. Therefore, this step is omitted. 


\section{DISCUSSION AND CONCLUSION}

This paper investigated the generation mechanism of resonance phenomenon through the system dynamics model in the oligopolistic competition supply chain. A stimulus (sudden one-time demand increase) triggered the reinforcing loop (shortage game and allocation loop), then the loop made resonance phenomenon. The result of this study concludes that the phenomenon is related with reinforcing loop, balancing loop and delay and needs triggering of reinforcing loop. This paper also tested that balancing loop with delay did not make the resonance. The long delay can cause the increase of inventory and the inventory cannot evoke the shortage game. That is, reinforcing loop (by shortage game) is necessary factor for the phenomenon.

This study has some implications for practice. Many companies have used lean management. The lean management requires short lead time and low inventory. Short lead time decreases the inventory and can trigger the reinforcing loop. This implies that lean management could not decrease the lead time unlimitedly because lead time can make the resonance phenomenon. Many companies are making the lean supply chain for efficiency but it can lead to an unstable and anti-resilient status. This paper also revealed that a small stimulus can give rise to disruption of the whole system. In this paper the stimulus might be intended but can be caused by mistakes or errors. For a resilient system, it is necessary to have more inventories (for vulnerability) and short lead-time (for recovery) at the same time. This implies that there is a conflict between lean management and resilience in the perspective of inventory.

This paper also has some limitations. So it is difficult to generalise the results. The simulation model in this study includes only 1 wholesaler and 2 retailers and has limited numbers of loops. The range of supply chain in the real world is wider than this model. In particular, this model has just one reinforcing model presented by shortage game. Although this model has validity and the loops are built based on other studies, the system in the real world has more loops and is more complex. But recall that the purpose of this study is mainly to investigate the generation mechanism of resonance phenomenon. For this purpose, we need a simple model with a minimum number of loops. We expect that the simple model helps you understand the resonance phenomenon.

\section{REFERENCES}

[1] Miragliotta, G. (2006). Layers and mechanisms: A new taxonomy for the bullwhip effect, International Journal of Production Economics, Vol. 104, No. 2, 365-381, doi:10.1016/ j.ijpe.2005.10.001

[2] Lee, H. L.; Padmanabhan, V.; Whang, S. (1997). The bullwhip effect in supply chains, MIT Sloan Management Review, Vol. 38, No. 3, 93-102

[3] Dejonckheere, J.; Disney, S. M.; Lambrecht, M. R.; Towill, D. R. (2003). Measuring and avoiding the bullwhip effect: a control theoretic approach, European Journal of Operational Research, Vol. 147, No. 3, 567-590, doi:10.1016/S0377-2217(02)00369-7

[4] Sterman, J. D. (2000). Business dynamics: systems thinking and modeling for a complex world, McGraw-Hill, Boston

[5] Croson, R.; Donohue, K. (2006). Behavioral causes of the bullwhip effect and the observed value of inventory information, Management Science, Vol. 52, No. 3, 323-336, doi:10.1287/ mnsc. 1050.0436

[6] Disney, S. M.; Towill, D. R. (2003). On the bullwhip and inventory variance produced by an ordering policy, Omega, Vol. 31, No. 3, 157-167, doi:10.1016/S0305-0483(03)00028-8

[7] Moon, S.-A. (2004). The relationships among manufacturer product strategy, supply chain structure and supply chain inventory, Asia Pacific Journal of Marketing and Logistics, Vol. 16, No. 2, 20-45, doi: $10.1108 / 13555850410765168$ 
[8] Moon, S.-A.; Kim, D.-J. (2005). Systems thinking ability for supply chain management, Supply Chain Management: An International Journal, Vol. 10, No. 5, 394-401, doi:10.1108/ 13598540510624214

[9] Buchmeister, B. (2008). Investigation of the bullwhip effect using spreadsheet simulation, International Journal of Simulation Modelling, Vol. 7, No. 1, 29-41, doi:10.2507/ IJSIMM07(1)3.093

[10] Buchmeister, B.; Friscic, D.; Palcic, I. (2013). Impact of demand changes and supply chain's level constraints on bullwhip effect, Advances in Production Engineering \& Management, Vol. 8, No. 4, 199-208, doi:10.14743/apem2013.4.167

[11] Wieland, A. (2013). Selecting the right supply chain based on risks, Journal of Manufacturing Technology Management, Vol. 24, No. 5, 652-668, doi:10.1108/17410381311327954

[12] Perrow, C. (1999). Organizing to reduce the vulnerabilities of complexity, Journal of Contingencies and Crisis Management, Vol. 7, No. 3, 150-155, doi:10.1111/1468-5973.00108

[13] Iakovou, E.; Vlachos, D.; Xanthopoulos, A. (2007). An analytical methodological framework for the optimal design of resilient supply chains, International Journal of Logistics Economics and Globalization, Vol. 1, No. 1, 1-20, doi:10.1504/IJLEG.2007.014498

[14] Carvalho, H.; Barroso, A. P.; Machado, V. H.; Azevedo, S.; Cruz-Machado, V. (2012). Supply chain redesign for resilience using simulation, Computers \& Industrial Engineering, Vol. 62, No. 1, 329-341, doi:10.1016/j.cie.2011.10.003

[15] Christopher, M.; Peck, H. (2004). Building the resilient supply chain, The International Journal of Logistics Management, Vol. 15, No. 2, 1-14, doi:10.1108/09574090410700275

[16] Chopra, S.; Sodhi, M. S. (2014). Reducing the risk of supply chain disruptions, MIT Sloan Management Review, Vol. 55, No. 3, 73-80

[17] Supsomboon, S.; Vajasuvimon, A. (2016). Simulation model for job shop production process improvement in machine parts manufacturing, International Journal of Simulation Modelling, Vol. 15, No. 4, 611-622, doi:10.2507/IJSIMM15(4)3.352

[18] Fisher, M. L. (1997). What is the right supply chain for your product?, Harvard Business Review, March/April Issue, 105-116

[19] Helbing, D.; Lammer, S.; Seidel, T.; Seba, P.; Platkowski, T. (2004). Physics, stability, and dynamics of supply networks, Physical review E, Vol. 70, No. 6, Paper 066116, doi:10.1103/PhysRevE.70.066116

[20] Tang, C. S. (2006). Robust strategies to mitigating supply chain disruptions, International Journal of Logistics Research and Applications, Vol. 9, No. 1, 33-45, doi:10.1080/ 13675560500405584

[21] Craighead, C. W.; Blackhurst, J.; Rungtusanatham, M. J.; Handfield, R. B. (2007). The severity of supply chain disruptions: design characteristics and mitigation capabilities, Decision Sciences, Vol. 38, No. 1, 131-156, doi:10.1111/j.1540-5915.2007.00151.x

[22] Marley, K. A.; Ward, P. T.; Hill, J. A. (2014). Mitigating supply chain disruptions - a normal accident perspective, Supply Chain Management: An International Journal, Vol. 19, No. 2, $142-$ 152, doi:10.1108/SCM-03-2013-0083

[23] Stecke, K. E.; Kumar, S. (2009). Sources of supply chain disruptions, factors that breed vulnerability, and mitigating strategies, Journal of Marketing Channels, Vol. 16, No. 3, 193-226, doi:10.1080/10466690902932551

[24] Hohenstein, N.-O.; Feisel, E.; Hartmann, E.; Giunipero, L. (2015). Research on the phenomenon of supply chain resilience: a systematic review, International Journal of Physical Distribution \& Logistics Management, Vol. 45, No. 1/2, 90-117, doi:10.1108/IJPDLM-05-2013-0128

[25] Chopra, S.; Sodhi, M. S. (2004). Managing risk to avoid supply-chain breakdown, MIT Sloan Management Review, Vol. 46, No. 1, 53-61

[26] Richardson, G. P. (1995). Loop polarity, loop dominance, and the concept of dominant polarity, System Dynamics Review, Vol. 11, No. 1, 67-88, doi:10.1002/sdr.4260110106

[27] Richardson, G. P.; Pugh III, A. L. (1981). Introduction to system dynamics modeling with DYNAMO, Productivity Press, Cambridge

[28] Ford, D. N. (1999). A behavioral approach to feedback dominance analysis, System Dynamics Review, Vol. 15, No. 1, 3-36, doi:10.1002/(SICI)1099-1727(199921)15:1<3::AID$\underline{\text { SDR159>3.0.CO;2-P }}$ 
[29] Sice, P.; Mosekilde, E.; Moscardini, A.; Lawler, K.; French, I. (2000). Using system dynamics to analyse interactions in duopoly competition, System Dynamics Review, Vol. 16, No. 2, 113-133, doi:10.1002/1099-1727(200022)16:2<113::AID-SDR189>3.0.CO;2-G

[30] Towill, D. R.; Naim, M. M.; Wikner, J. (1992). Industrial dynamics simulation models in the design of supply chains, International Journal of Physical Distribution \& Logistics Management, Vol. 22, No. 5, 3-13, doi:10.1108/09600039210016995

\section{APPENDIX: Parameter, Variables and Equations}

\section{Parameters}

$\overline{\text { FINAL TIME }}=200$ Day, INITIAL TIME $=0$ Day, TIME STEP $=1$ Day

R1Demand $=100+100 * P U L S E(11,1)$, R2Demand $=100$ unit

Adjustment time $=2$ Day $=$ RlAdjustment time for Inventory $=$ RlAdjustment time for Supply Line $=$ RlAdjustment time $=$ RlShipment time $=$ R1Target Days for Inventory $=$ R1Target Days for Supply Line $=$ R2Adjustment time for Inventory $=$ R2Adjustment time for Supply Line $=$ $R 2$ Adjustment time $=R 2$ Shipment time $=R 2$ Target Days for Inventory $=R 2$ Target Days for Supply Line $=$ WAdjustment time for Inventory $=$ WAdjustment time for Supply Line = WShipment time = WTarget Days for Inventory = WTarget Days for Supply Line

\section{Variables and Equations}

RlAllocated Quantity =MIN(WR1Backlog, WInventory*XIDZ( WR1Backlog, WR1Backlog +WR2Backlog, 0))

R1Backlog = INTEG (R1BLin-R1BLout,R1Demand $),$ R1BLin=R1Demand, R1BLout=R1Consume

RlConsume $=M I N(R 1$ Backlog, Rlinventory $)$

$R 1$ ifference of Inventory $=(R 1$ Target Inventory-R1Inventory $) / R 1$ Adjustment time for Inventory

R1Difference of Supply Line $=($ R1Target Supply Line-R1Supply Line $) / R 1$ Adjustment time for Supply Line

RlInventory = INTEG (R1Shipment-RIConsume, R1Target Inventory)

R1Order Quantity $=\operatorname{MAX}\left(0, M I N\left(5^{*}(\right.\right.$ R1Perceived Demand + R1Difference of Inventory + R1Difference of Supply Line $)$, XIDZ( RIPerceived Demand+R1Difference of Inventory+R1Difference of Supply Line, 1-R1Perceived Shortage Ratio, R1Perceived Demand + R1Difference of Inventory + R1Difference of Supply Line)))

R1Perceived Allocated Quantity=SMOOTHI(R1Allocated Quantity, R1Adjustment time, 100)

R1Perceived Demand=SMOOTH(R1Demand, R1Adjustment time for Inventory)

RlPerceived Order Quantity=SMOOTHI(RIOrder Quantity, RlAdjustment time, 100)

R1Perceived Shortage Ratio=MAX(0, MIN(1, XIDZ(R1Perceived Order Quantity-R1Perceived Allocated Quantity, R1Perceived Order Quantity, 0)))

R1Purchase $=$ RlAllocated Quantity, R1Shipment=R1Supply Line/R1Shipment time

R1Supply Line = INTEG (R1Purchase-R1Shipment,R1Target Supply Line

RITarget Inventory=R1Target Days for Inventory*R1Perceived Demand

R1Target Supply Line $=$ RlPerceived Demand $*$ RlTarget Days for Supply Line

R2Allocated Quantity $=$ MIN (WR2Backlog, WInventory*XIDZ( WR2Backlog, WR1Backlog + WR2Backlog, 0)

$R 2$ Backlog $=I N T E G(R 2 B L i n-R 2 B L o u t, R 2$ Demand $), R 2 B$ Lin $=R 2$ Demand, R2BLout=R2Consume,

R2Consume $=\operatorname{MIN}($ R2Backlog, R2Inventory)

$R 2$ Difference of Inventory $=(R 2$ Target Inventory-R2Inventory $) / R 2$ Adjustment time for Inventory

$R 2$ Difference of Supply Line $=($ R2Target Supply Line-R2Supply Line $) / R 2 A d j u s t m e n t$ time for Supply Line

R2Inventory $=$ INTEG (R2Shipment-R2Consume, R2Target Inventory)

R2Order Quantity $=\operatorname{MAX}(0, M I N(5 *(R 2$ Perceived Demand $+R 2$ Difference of Inventory $+R 2$ Difference of Supply Line $), X I D Z(R 2 P e r c e i v e d$ Demand $+R 2$ Difference of Inventory $+R 2$ Difference of Supply Line, 1-R2Perceived Shortage Ratio, R2Perceived Demand $+R 2$ Difference of Inventory $+R 2$ Difference of Supply Line)))

R2Perceived Allocated Quantity=SMOOTHI(R2Allocated Quantity, R2Adjustment time, 100)

$R 2$ Perceived Demand $=S M O O T H(R 2 D e m a n d, R 2 A d j u s t m e n t$ time for Inventory)

R2Perceived Order Quantity=SMOOTHI(R2Order Quantity, R2Adjustment time, 100)

R2Perceived Shortage Ratio $=$ MAX (0, MIN (1, XIDZ(R2Perceived Order Quantity-R2Perceived Allocated Quantity, R2Perceived Order Quantity, 0)) $R 2$ Purchase $=$ R2Allocated Quantity, R2Shipment $=$ R2Supply Line $/$ R2Shipment time

R2Supply Line $=I N T E G$ (R2Purchase-R2Shipment,R2Target Supply Line)

$R 2$ Target Inventory $=R 2$ Target Days for Inventory $* 2$ Perceived Demand

R2Target Supply Line $=R 2$ Perceived Demand $*$ R2Target Days for Supply Line

WAdjustment time $=$ Adjustment time, WAllocated Quantity $=$ WOrder Quantity

WConsume $=\operatorname{MIN}$ (WInventory, R1Allocated Quantity + R2Allocated Quantity)

WDemand=R1Order Quantity+R2Order Quantity

WDifference of Inventory $=($ WTarget Inventory-WInventory $) /$ WAdjustment time for Inventory

WDifference of Supply Line $=($ WTarget Supply Line-WSupply Line $) /$ WAdjustment time for Supply Line

WInventory $=$ INTEG (WShipment-WConsume,WTarget Inventory)

WOrder Quantity =MIN(WPerceived Demand $* 2$, MAX (0, WPerceived Demand + WDifference of Inventory+WDifference of Supply Line)/(1-WPerceived Shortage Ratio $))$ WPerceived Demand=SMOOTH(WDemand, WAdjustment time for Inventory)

WPurchase $=$ WOrder Quantity

WR1Backlog = INTEG (WR1BLin-WR1BLout, R1Order Quantity)

WR1BLin=R1Order Quantity, WR1BLout=R1Allocated Quantity

WR2Backlog = INTEG (WR2BLin-WR2BLout,R2Order Quantity)

WR2BLin=R2Order Quantity, WR2BLout=R2Allocated Quantity

WShipment $=$ WSupply Line/WShipment time

WSupply Line = INTEG (WPurchase-WShipment, WTarget Supply Line)

WTarget Inventory $=$ WTarget Days for Inventory*WPerceived Demand

WTarget Supply Line $=$ WPerceived Demand $*$ WTarget Days for Supply Line

Atomic Behaviour Pattern Indicator=(((WOrder Quantity-SMOOTH(WOrder Quantity, TIME STEP))/TIME STEP)-SMOOTH (((WOrder QuantitySMOOTH(WOrder Quantity, TIME STEP))/TIME STEP), TIME STEP))/TIME STEP 